\title{
Toxicity and Oviposition Deterrent Activities of Thyme Essential Oils against Anopheles arabiensis
}

\author{
Destaw Damtie $\mathbb{D}^{1}$ and Yalemtsehay Mekonnen ${ }^{2}$ \\ ${ }^{1}$ Department of Biology, Bahir Dar University, Bahir Dar, Amhara Regional State, Ethiopia \\ ${ }^{2}$ Department of Microbial Cellular and Molecular Biology, Addis Ababa University, Addis Ababa, Ethiopia \\ Correspondence should be addressed to Destaw Damtie; zegades96@gmail.com
}

Received 7 October 2020; Revised 24 March 2021; Accepted 28 May 2021; Published 8 June 2021

Academic Editor: Leonardo Dapporto

Copyright (C) 2021 Destaw Damtie and Yalemtsehay Mekonnen. This is an open access article distributed under the Creative Commons Attribution License, which permits unrestricted use, distribution, and reproduction in any medium, provided the original work is properly cited.

\begin{abstract}
Background. Malaria is one of the deadliest mosquito-borne diseases in sub-Saharan Africa and Ethiopia. Owing to their costs and environmental issues, synthetic insecticides are poor choices to control mosquitoes. Plant-based products can be considered as safe and biodegradable alternatives. The present study aimed to test the toxicity and oviposition deterrent activities of Thymus serrulatus and Thymus schimperi essential oils (EOs) against Anopheles arabiensis. Methods. Thyme EOs were extracted by hydrodistillation using the Clevenger-type apparatus. They were named Tar, Ala, and Yil after the areas of thyme collection Tarmaber, Alamata, and Yilmana Densa, respectively. Laboratory-based tests were used to determine the larvicidal, adulticidal, oviposition deterrent, and half lethal dose (LD50) of each EO. Results. The concentrations of $100 \mu \mathrm{l} / \mathrm{L}$ and $50 \mu \mathrm{l} / \mathrm{L}$ resulted in complete mortalities of larvae and adults, respectively, for all the three Eos considered. The EOs exhibited high repellency with oviposition activity index of $-1(\mathrm{OAI}=-1)$ at concentrations of $50 \mu \mathrm{l} / \mathrm{L}(\mathrm{Tar}), 100 \mu \mathrm{l} / \mathrm{L}(\mathrm{Ala})$, and $200 \mu \mathrm{l} / \mathrm{L}$ (Yil). Conclusions. The EOs of T. serrulatus and T. schimperi were effective against larvae and adult mosquitoes at small doses and resulted in oviposition deterrence at doses from 50 to $200 \mu \mathrm{l} / \mathrm{L}$. Thus, these EOs are promising mosquitocides and oviposition deterrents. But, further tests both in the presence of already known and effective deterrents and field trials are required.
\end{abstract}

\section{Introduction}

Mosquitoes transmit different diseases including malaria [1-3]. Malaria, the most deadly mosquito-borne disease [4], kills an estimated amount of more than 600,000 people every year, mainly children under five years of age in sub-Saharan Africa [4]. By 2015, the share of Ethiopia to the world malaria cases was six percent [5]. The emergence of resistant strains of Plasmodium falciparum and lack of an effective malaria vaccine makes vector control an important way to interrupt the cycle of disease transmission [4].

Synthetic insecticides such as organochlorine and organophosphate compounds are major tools in mosquito control [6]. Nevertheless, lack of novel insecticides, high cost of synthetic insecticides, and concern for environmental sustainability make synthetic insecticides poor choices $[1-3,7-11]$.
Consequently, there is a rise in search of alternative vector control strategies $[6,9]$. Plant-derived compounds have a good perspective as alternatives to fight mosquitoborne diseases [9]. Thymus species are among many plants with mosquitocidal activities [9].

Studies show that different thyme species have larvicidal, adulticidal, and oviposition deterrent activities against insects. The essential oils (EOs) of Thymus broussonetii and Thymus maroccanus had larvicidal activities against $C$. pipiens larvae [12], EOs of T. vulgaris L. against greater wax moth, Galleria mellonella L. larvae [13], and thymol and 1,8-cineole isolated from thyme EOs against Aedes aegypti larvae [1]. Furthermore, the essential oils obtained from T. vulgaris and T. satureioides were effective against Culex quinquefasciatus Say larvae [14]; EO and components (thymol and carvacrol) of T. vulgaris are against larvae of lesser mealworm, Alphitobius diaperinus Panzer [15]. 
The insecticidal activity of thyme EOs is reported by different studies. T. serpyllum EO against Aedes, Anopheles, and Culex mosquitoes [16]; T. transcaspicus EOs against $A$. stephensi [17]; T. cariensis and T. cilicicus EOs against Callosobruchus maculatus (cowpea weevil) [18]; T. capitatus, T. bleicherianus, and T. satureioides EOs against Sitophilus oryzae [19]; T. numidicus EO against Rhizopertha dominica [20]; and carvacrol and thymol derived from T. vulgaris against Pochazia shantungensis [21].

The oviposition deterrent activity of thyme EOs is not well reported. T. vulgaris EO is reported to have oviposition deterrent activity against Acanthoscelides obtectus [22]. However, there are no reports about the larvicidal, adulticidal, and oviposition deterrent activities of the EOs of the two Ethiopian endemic thyme species, T. serrulatus and $T$. schimperi. Thus, the present study is aimed at evaluating the larvicidal, adulticidal, and oviposition deterrent activities of the EOs of these thyme species from Ethiopia against $A$. arabiensis mosquitoes.

\section{Materials and Methods}

2.1. Plant Material Collection and Identification. Aerial parts of T. serrulatus and T. schimperi were collected between July and September 2013 from Alamata (lat/long dec. 13.69589, 37.0542153) (Tigray region) and Yilmana Densa (lat/long dec. 12.28943, 37.0325366) and Tarmaber (lat/long dec. 10.89386, 37.0580250) districts (Amhara region) in Ethiopia. These plants were collected from the wild, and they are not endangered species. Consequently, specific permission was not required for the collection and investigation of these plants. The Thymus species were identified by Mr. Melaku Wondafrash, a botanist working in the National Herbarium of Addis Ababa University, Addis Ababa, Ethiopia, and voucher specimens were deposited in the herbarium.

2.2. Preparation of Essential Oils. The investigators added fine powder $(200 \mathrm{~g})$ of each plant to $2 \mathrm{~L}$ of distilled water (with vegetal material/extraction solvent rate $=1 / 10(w / v)$ in a $4 \mathrm{~L}$ round bottom glass flask and subjected to water distillation for three hours using a Clevenger-type apparatus in the Insect Science Laboratory of Zoological Science Department of Addis Ababa University to extract the essential oils. After extraction, the volume of the EOs was measured, dried over anhydrous sodium sulfate, stored in brown glass bottles to reduce the intensity of light, and placed at $4^{\circ} \mathrm{C}$ until used for the experiments.

2.3. Larvicidal Bioassay. Larvae of A. arabiensis were reared in larval rearing trays in the insectary of the Ethiopian Public Health Institute (EPHI). Larvae were supplied daily with $0.5 \mathrm{~g}$ larval food made of dog biscuit and brewery yeast $3: 2$ (w:w ratio) [23]. The EOs of Ala, Yil, and Tar were made in concentrations of $12.5,25,50,100$, and $200 \mu \mathrm{l} / \mathrm{L}$ in acetone. The chemical composition of these EOs was previously characterized and published [24]. Ala was found to be highly thymol $(65.63 \%)$, Yil (carvacrol $=80.84 \%$ ), and Tar (thymol: carvacrol $=48.84 \%: 42.12 \%)$ chemotypes. A total of 25 third and fourth instar larvae of $A$. arabiensis were placed in each $300 \mathrm{ml}$ white enamel cup containing $149 \mathrm{ml}$ of distilled water [16] (Figure 1). After three hours of larval acclimatization, $1 \mathrm{~mL}$ of desired concentration of thyme EOs $(12.5,25,50$, 100 , and $200 \mu \mathrm{l} / \mathrm{L}$ ) was added to each beaker to make a final volume of $150 \mathrm{~mL}$. Each dose of the three EOs was tested three times. An equal volume of acetone was used as a negative control. Larval mortality was recorded $24 \mathrm{hr}$ postexposure. Larvae were confirmed dead when they failed to move after gentle probing them with a needle [25].

2.4. Adulticidal Test. Fumigating adulticidal activity was tested by airtight fumigation in conical flasks, as described by Pavela et al. [26]. Twenty nonblood-fed females (2-6 days old) were placed in each $250 \mathrm{ml}$ conical flask (Figure 2) because older blood-fed females have reduced susceptibility to insecticides [27]. A $10 \mu \mathrm{l}$ volume of the EO solution of five doses $3.125,6.25,12.5,25$, and $50 \mu \mathrm{l} / \mathrm{L}$ in acetone was immediately dropped onto a filter paper $(1 \times 3 \mathrm{~cm})$ with a micropipette. A cork stopper was used to seal each conical flask, and the filter paper was placed at the base of the cork. The controls were treated under the same conditions with pure acetone. The conical flasks were sealed tightly and placed in a room at $26^{\circ} \mathrm{C}$ for four hours [28]. Mortality was determined after $24 \mathrm{~h}$ of exposure after being transferred to clean cages.

2.5. Oviposition Deterrent Bioassay. Fifteen gravid females (eight to ten days old, four days after blood feeding) were transferred to each mosquito cage $(45 \times 30 \times 30 \mathrm{~cm})$ (Figure 3). Serial dilutions of EOs were made in dimethylsulfoxide (DMSO). We used DMSO instead of acetone because acetone is attractant to mosquitoes and could affect our findings [29]. In the multiple concentration test, five cups, each containing $100 \mathrm{~mL}$ distilled water with a $9 \mathrm{~cm}$ piece of white filter paper for oviposition as well as EOs at concentrations of $12.5,25,50,100$, and $200 \mu \mathrm{l} / \mathrm{L}$, were placed in each cage. The sixth cup containing DMSO served as a negative control in each cage. The positions of the plastic cups were alternated between the different replicates to nullify any effect of position on oviposition. Three replicates for each concentration were run with cages placed side by side for each bioassay. A sucrose solution (10\%) was available at all times. The room was set to have a temperature of $26^{\circ} \mathrm{C}$ and relative humidity of 75-85\%. After $24 \mathrm{hr}$, the number of eggs laid in treated and control cups was counted under a hand lens. Then, the oviposition activity index (OAI) was calculated using the following formula [7].

$$
O A I=\frac{N T-N S}{N T+N S}
$$

where NT is the total number of eggs in the test solution and NS is the total number of eggs in the control solution. EO doses with oviposition active index of +0.3 and above were considered as attractants while those with -0.3 and below as repellents [7]. 


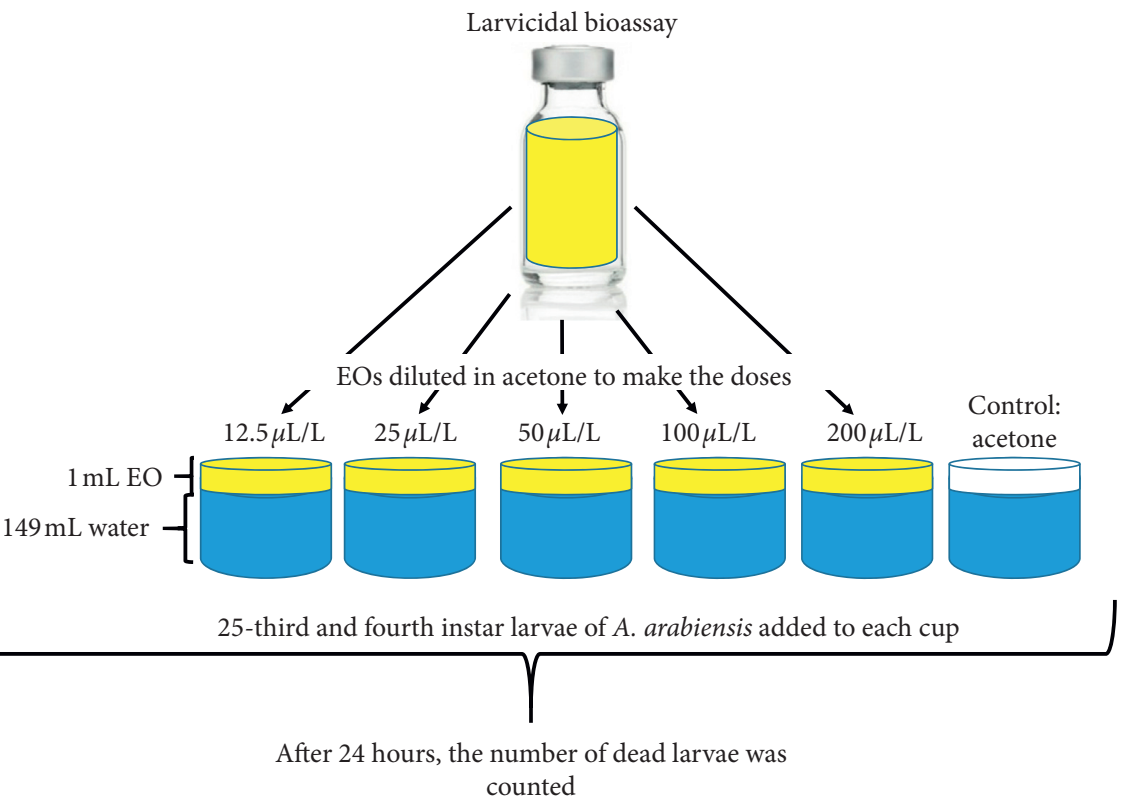

FiguRE 1: Larvicidal bioassay set-up.

20 nonblood-fed female mosquitoes were added in each $250 \mathrm{~mL}$ flask

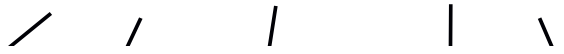

$10 \mu \mathrm{l}$ of each EO dose diluted with acetone was applied on the lids of the flasks and stayed for 4 hours after which the lids were replaced by mesh clothes

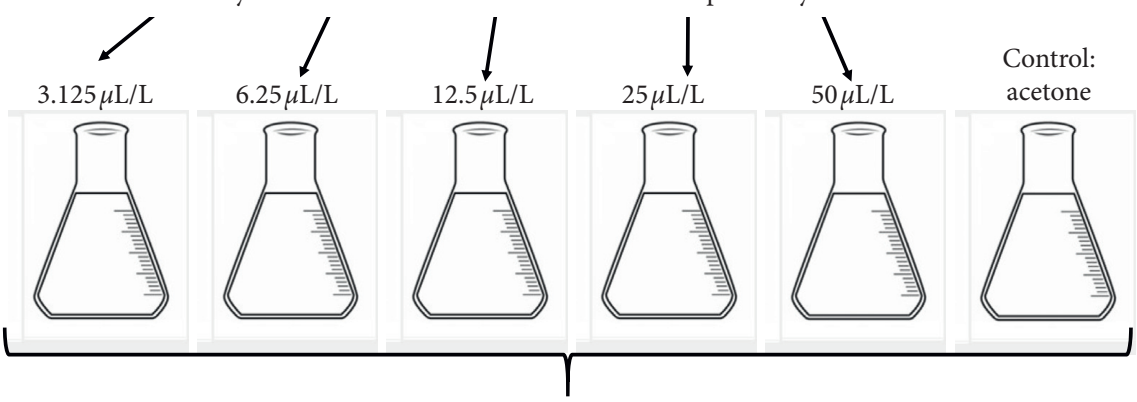

After 24 hours, the number of dead mosquitoes in each flask was counted

Figure 2: The fumigation test set-up.

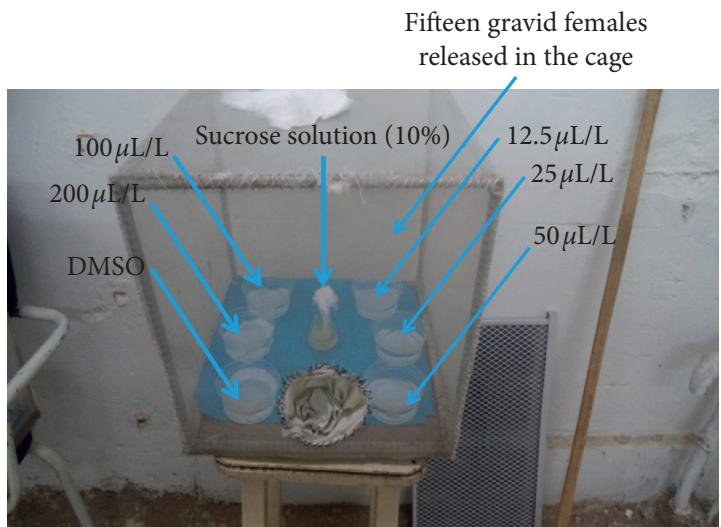

FIgURE 3: Oviposition deterrent test set-up.
2.6. Statistical Analysis. Data for the larvicidal, adulticidal, and oviposition deterrent activities were expressed as mean \pm SEM and analyzed statistically using one-way analysis of variance (ANOVA) followed by LSD post hoc multiple comparisons. The minimum level of significance was set at $P<0.05$. Statistics was computed using SPSS programme version 20 and SAS 9.2.

\section{Results}

3.1. Larvicidal Activity. The 200 and $100 \mu \mathrm{l} / \mathrm{L}$ doses of the three tested EOs (Ala, Yil, and Tar) showed complete mortality of larvae. At $50 \mu \mathrm{l} / \mathrm{L}$ concentration, Yil, Tar, and Ala EOs resulted in larval mortality rates of $81 \%, 80 \%$, and $37 \%$, respectively (Figure 4 ). In the same way, at $25 \mu \mathrm{l} / \mathrm{L}$ EO 


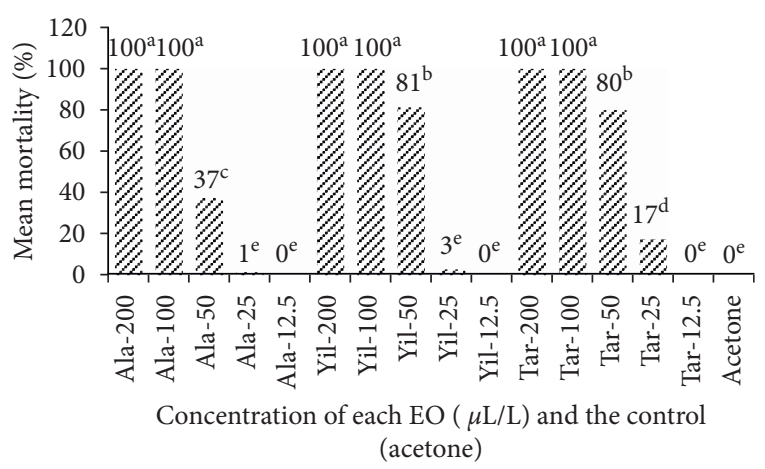

FIgURe 4: Percent mortality of larvae at different doses of EOs and acetone.

doses, larval mortalities were 17\% (Tar), 3\% (Yil), and 1\% (Ala). At the dose of $50 \mu \mathrm{l} / \mathrm{L}$, EOs of Yil and Tar killed larvae with mortality rates significantly higher than that of Ala (Table 1). The mean number of larvae that died due to the $25 \mu \mathrm{l} / \mathrm{L}$ of Tar was significantly higher than that of Ala and Yil EOs (Figure 4). On the other hand, the $25 \mu \mathrm{l} / \mathrm{L}$ doses of Ala and Yil as well as the $12.5 \mu \mathrm{l} / \mathrm{L}$ doses of all the three EOs did not result in larvicidal activities significantly higher than that of the negative control (acetone). The best larvicidal activity was EO of Tar followed by Yil and lastly by Ala EOs.

3.2. Adulticidal Test. The fumigation adulticidal activity of the three EOs showed dose-dependent activities against adult female $A$. arabiensis mosquitoes (Figure 5). For example, at $50 \mu \mathrm{l} / \mathrm{L}$ concentration, the EOs of Ala, Yil, and Tar resulted in $100 \%$ death of adult female mosquitoes. The death rates at $25 \mu \mathrm{l} / \mathrm{L}$ of the EOs of Tar, Yil, and Ala were 95, 90 , and 85 , respectively, reaching $100 \%$ at $50 \mu \mathrm{l} / \mathrm{L}$. At the dose $12.5 \mu \mathrm{l} / \mathrm{L}$, the adulticidal activity of Tar was significantly higher than that of Ala and Yil which in turn resulted in mosquitocidal activities significantly higher than that of the 6.25 and $3.125 \mu \mathrm{l} / \mathrm{L}$ doses (Table 1). The $6.25 \mu \mathrm{l} / \mathrm{L}$ doses of Yil and Tar EOs too showed mosquitocidal activities significantly higher than that of the $6.25 \mu \mathrm{l} / \mathrm{L}$ of Ala, the $3.125 \mu \mathrm{l} / \mathrm{L}$ of Ala, Yil, and Tar, and the negative control (acetone). Therefore, the EOs of Tar acted as adulticidal even at lower doses followed by Yil. The Ala EO was found to be the least effective of the three EOs. This shows that the adulticidal activity of the EOs was in the order of Tar $>$ Yil $>$ Ala (Figure 5).

3.3. Oviposition Deterrent Activity. The result of the oviposition deterrent bioassay is presented as the oviposition activity index (OAI) (Figure 6). The OAI of the EOs of Ala and Tar was below -0.3 at all test concentrations. Similar findings were observed in Yil EO at the doses of 200, 100, and $50 \mu \mathrm{l} / \mathrm{L}$. On the other hand, the control (DMSO) did not result in any oviposition deterrent effect.

\section{Discussion}

In the larvicidal, adulticidal, and oviposition deterrent tests, all the EOs tested (Ala, Yil, and Tar) at higher doses resulted in mosquitocidal activities. These mosquitocidal activities
TABLE 1: ANOVA result of the mean number of larval $(n=25)$ and adult $(n=20)$ deaths due to Ala, Yil, and Tar EOs.

\begin{tabular}{lcccc}
\hline \multirow{2}{*}{ EO } & \multicolumn{2}{c}{ Larvicidal activity } & \multicolumn{2}{c}{ Adulticidal activity } \\
& Dose $(\mu \mathrm{l} / \mathrm{L})$ & Mean \pm SEM & Dose $(\mu \mathrm{l} / \mathrm{L})$ & Mean \pm SEM \\
\hline \multirow{4}{*}{ Ala } & 200 & $25 \pm 0.0^{\mathrm{a}}$ & 50 & $20.00 \pm 0.00^{\mathrm{a}}$ \\
& 100 & $25 \pm 0.0^{\mathrm{a}}$ & 25 & $16.67 \pm 0.88^{\mathrm{b}}$ \\
& 50 & $9.33 \pm 1.85^{\mathrm{c}}$ & 12.5 & $9.33 \pm 0.88^{\mathrm{d}}$ \\
& 25 & $0.33 \pm 0.33^{\mathrm{e}}$ & 6.25 & $1.33 \pm 0.33^{\text {ef }}$ \\
& 12.5 & $0 \pm 0.0^{\mathrm{e}}$ & 3.125 & $0.00 \pm 0.00^{\mathrm{f}}$ \\
\hline \multirow{4}{*}{ Yil } & 200 & $25 \pm 0.0^{\mathrm{a}}$ & 50 & $20.00 \pm 0.00^{\mathrm{a}}$ \\
& 100 & $25 \pm 0.0^{\mathrm{a}}$ & 25 & $18.33 \pm 0.67^{\mathrm{ab}}$ \\
& 50 & $20.33 \pm 3.18^{\mathrm{b}}$ & 12.5 & $10.33 \pm 1.85^{\mathrm{d}}$ \\
& 25 & $0.67 \pm 0.67^{\mathrm{e}}$ & 6.25 & $2.33 \pm 0.33^{\mathrm{e}}$ \\
& 12.5 & $0 \pm 0.0^{\mathrm{e}}$ & 3.125 & $0.00 \pm 0.00^{\mathrm{f}}$ \\
\hline \multirow{4}{*}{ Tar } & 200 & $25 \pm 0.0^{\mathrm{a}}$ & 50 & $20.00 \pm 0.00^{\mathrm{a}}$ \\
& 100 & $25 \pm 0.0^{\mathrm{a}}$ & 25 & $18.67 \pm 0.67^{\mathrm{a}}$ \\
& 50 & $20 \pm 0.58^{\mathrm{b}}$ & 12.5 & $13.00 \pm 0.58^{\mathrm{c}}$ \\
& 25 & $4.33 \pm 2.6^{\mathrm{d}}$ & 6.25 & $3.00 \pm 0.58^{\mathrm{e}}$ \\
Control & Acetone & $0 \pm 0.0^{\mathrm{e}}$ & Acetone & $0.00 \pm 0.00^{\mathrm{f}}$ \\
\hline
\end{tabular}

Means with the same letter are not significantly different $(p>0.05)$. Least significant difference $=3.1547$.

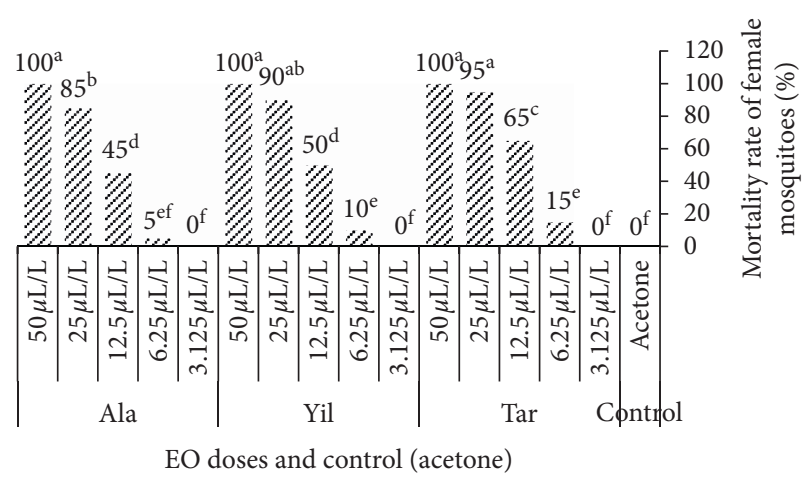

Figure 5: Percent mortality of adult female mosquitoes due to the different concentrations of Ala, Yil, and Tar EOs and the negative control (acetone).

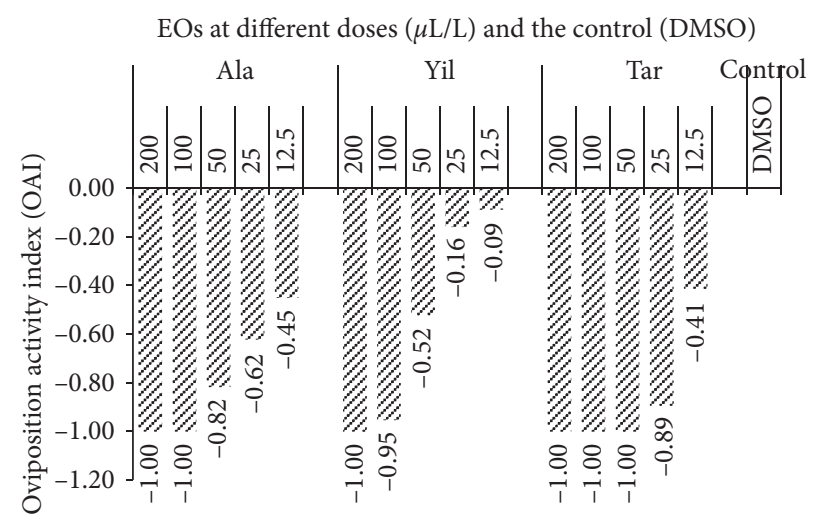

Figure 6: Oviposition activity index (OAI) values of three EOs against $A$. arabiensis.

could be associated with the presence of EO components, mainly thymol and carvacrol [30]. The percentages of thymol and carvacrol were $65.63 \%$ and $6.68 \%$ (Ala), $6.52 \%$ and 
$80.84 \%$ (Yil), and $48.84 \%$ and $42.12 \%$ (Tar), respectively [24]. Tar with (thymol + carvacrol $=90.96 \%$ ) was the most effective EO followed by that of Yil (thymol + carvacrol $=87.36 \%$ ) and Ala (thymol + carvacrol $=72.31 \%$ ). This difference is indicative of the importance of these phenolic monoterpenes as insecticides. Furthermore, the EO of Tar was with almost equal proportions of thymol/carvacrol (1.16/1), Ala was much of thymol type (thymol/carvacrol $=9.8 / 1$ ), and Yil was more of carvacrol type (thymol/carvacrol $=1 / 12.4$ ) [24]. Thus, the mosquitocidal activities of Tar may be due to either the synergistic activities of the two monoterpenes [30]. Whereas, the activities of Ala may be more due to thymol [26] and that of Yil more due to carvacrol [30-32].

In the present study, the larvicidal and adulticidal activity was Tar $>$ Yil $>$ Ala. The oviposition deterrent activity was Tar $>$ Ala $>$ Yil. The synergistic effects of thymol and carvacrol are probably responsible for Tar's effectiveness [31]. Tar and Ala had much more thymol than carvacrol. Yil had more carvacrol than thymol. Thymol is known to have a higher deterrent effect on oviposition than carvacrol, so are Tar and Ala (thymol chemotypes) [26]. But Yil (carvacrol chemotype) was more toxic to larvae and adults than Ala probably because carvacrol is toxic to insects than thymol [31-33].

Thymol and carvacrol are known larvicidal against various insects. For example, they were found to be strong larvicidal against lesser mealworm (A. diaperinus) where the pure components had strong activities when compared with the oil; $1 \%$ thyme oil, thymol, and carvacrol caused mortality of $50.0,86.67$, and $85 \%$, respectively [34]. These substances act as neurotoxins, growth regulators, antifeedants, and repellents [15]. Thymol affects the central nervous system, the longitudinal flight muscles, and neuromuscular junctions. It acts on GABA-sensitive sites in vivo, either by mimicking or facilitating the effects of this inhibitory neurotransmitter [35]. It too shows a repellent action against mosquitoes [36].

Other components of thyme (camphor, cineole, methyl eugenol, limonene, and myrcene) also act as repellents and larvicidal against mosquitoes [36]. The sesquiterpene (Z)caryophyllene inhibits the activity of several enzymes such as acetylcholinesterase, glutathione s-transferase, and carboxylesterase, which are important detoxification enzymes of insect body, involved in the detoxification of antifeedants, fumigants, and pesticides [30].

Thus, it is evident that the $\mathrm{EO}$ of Tar containing thymol (48.84\%), carvacrol $(42.12 \%)$, linalool (2.97\%), $\alpha$-terpineol $(0.95 \%)$, and t-caryophyllene $(0.43 \%)$ is a strong mosquitocidal [24]. Similarly, Yil EO possessed carvacrol (80.84\%), thymol (6.52\%), linalool (0.25\%), and t-caryophyllene $(0.82 \%)$ [24], all of which have insecticide properties as mentioned above. The Ala EO also had thymol (65.63\%), carvacrol (6.68\%), linalool (3.29\%), and t-caryophyllene (1.5\%) [24] all of which are mosquitocidal. Thus, the three EOs (Tar, Yil, and Ala) have components with mosquitocidal activities.

Carvacrol has broad insecticidal and acaricidal activities against agriculture, stored product, and medical pests, and it acts as a fumigant as well. Therefore, it can be inferred that carvacrol has a stronger insecticidal activity than thymol $[15,37]$ and that in combination with thymol its insecticidal potential decreases. This indicates the antagonism of the two phenols when used as an insecticide [37]. The results from Yil and Ala agree with these statements, in that the carvacrol type Yil is highly effective than the thymol type Ala. However, the presence of thymol and carvacrol in almost equal proportions in Tar had the best result contradicting the findings of Popoviæ and coworkers [37] which showed that the reduced impact of carvacrol is due to the presence of thymol. This difference may be due to the synergistic activities of these EOs [30] with other components of Tar EO. The larvicidal, adulticidal, and oviposition deterrent activities of the three EOs were very high. But, their validation is not possible because positive controls were not used for each test.

\section{Conclusion}

The EOs of T. serrulatus (from Ala and Yil), as well as T. shimperi (from Tar), acted as larvicidal, adulticidal, and oviposition deterrent against A.arabiensis third and fourth instar larvae, nongravid females, and gravid females, respectively. Tar was the best mosquitocidal EO followed by Yil and Ala EOs. All the tested doses of Tar and Ala and the higher doses of Yil acted as repellents. However, at lower doses, Yil acted neither as an oviposition deterrent nor as an attractant.

\section{Data Availability}

The data used to support the findings of this study are included within the article.

\section{Conflicts of Interest}

The authors declare that they have no conflicts of interest.

\section{Acknowledgments}

The authors acknowledge the Ethiopian Public Health Institute (EPHI) for providing laboratory facilities and the insectary.

\section{References}

[1] B. Conti, A. Canale, A. Bertoli, F. Gozzini, and L. Pistelli, "Essential oil composition and larvicidal activity of six mediterranean aromatic plants against the mosquito Aedes albopictus (Diptera: Culicidae)," Parasitology Research, vol. 107, no. 6, pp. 1455-1461, 2010.

[2] V. K. Dua, A. C. Pandey, and A. P. Dash, "Adulticidal activity of essential oil of Lantana camara leaves against mosquitoes," The Indian Journal of Medical Research, vol. 131, no. 3, pp. 434-9, 2010.

[3] A. Andemo, D. Yewhalaw, B. Alemayehu, and A. Ambelu, "Evaluation of the mosquitocidal effect of Birbira (Mellitia ferruginea) seed extract against Anopheles arabiensis (Diptera: Culicidae) from Ethiopia," Acta Tropica, vol. 136, pp. 68-73, 2014. 
[4] K. Karunamoorthi, A. Girmay, and S. Fekadu, "Larvicidal efficacy of Ethiopian ethnomedicinal plant Juniperus procera essential oil against Afrotropical malaria vector Anopheles arabiensis (Diptera: Culicidae)," Asian Pacific Journal of Tropical Biomedicine, vol. 4, pp. S99-S106, 2014.

[5] WHO, World Malaria Report 2016, World Health Organization, Geneva, Switzerland, 2016.

[6] M. Govindarajan, R. Sivakumar, A. Amsath, and S. Niraimathi, "Larvicidal efficacy of botanical extracts against two important vector mosquitoes," European Review for Medical and Pharmacological Sciences, vol. 16, no. 3, pp. 386-392, 2012.

[7] G. Elango, A. Bagavan, C. Kamaraj, A. Abdul Rahuman, and A. A. Rahuman, "Oviposition-deterrent, ovicidal, and repellent activities of indigenous plant extracts against Anopheles subpictus Grassi (Diptera: Culicidae)," Parasitology Research, vol. 105, no. 6, pp. 1567-1576, 2009.

[8] N. Aarthi and K. Murugan, "Larvicidal and smoke repellent activities of Spathodea campanulata P. Beauv. against the malarial vector Anopheles stephensi Lis (Diptera: Culicidae)," Journal of Phytology, vol. 2, no. 8, 2010.

[9] A. Ghosh, N. Chowdhury, and G. Chandra, "Plant extracts as potential mosquito larvicides," The Indian Journal of Medical Research, vol. 135, no. 5, pp. 581-98, 2012.

[10] J. Gokulakrishnan, E. Kuppusamy, D. Shanmugam, A. Appavu, and K. Kaliyamoorthi, "Pupicidal and repellent activities of Pogostemon cablin essential oil chemical compounds against medically important human vector mosquitoes," Asian Pacific Journal of Tropical Disease, vol. 3, no. 1, pp. 26-31, 2013.

[11] H. Atta and J. Reeder, World Malaria Day 2014: Invest in the Future, University Research Co., LLC (URC), Yangon, Myanmar, 2014.

[12] R. Belaqziz, R. Harrak, A. Romane, K. Oufdou, and M. A. E. ElFels, "Antimicrobial and insecticidal activities of the endemic Thymus broussonetti boiss. and Thymus maroccanus ball," Records of Natural Products, vol. 4, no. 4, p. 230, 2010.

[13] A. A. Owayss and A. A. Abd-Elgayed, "Potential efficacy of certain plant volatile oils and chemicals against greater wax moth, Galleria mellonella L.(lepidoptera: pyralidae)," Bulletin of the Entomological Society of Egypt, vol. 33, pp. 67-75, 2007.

[14] R. Pavela, "Larvicidal property of essential oils against Culex quinquefasciatus Say (Diptera: Culicidae)," Industrial Crops and Products, vol. 30, no. 2, pp. 311-315, 2009.

[15] M. Szczepanik, B. Zawitowska, and A. Szumny, "Insecticidal activities of Thymus vulgaris essential oil and its components (thymol and carvacrol) against larvae of lesser mealworm, Alphitobius diaperinus Panzer (Coleoptera: tenebrionidae)," Allelopathy Journal, vol. 30, no. 1, pp. 129-142, 2012.

[16] F. Massebo, M. Tadesse, T. Bekele, M. Balkew, and T. GebreMichael, "Evaluation on larvicidal effects of essential oils of some local plants against Anopheles arabiensis patton and Aedes aegypti linnaeus (Diptera, Culicidae) in Ethiopia," African Journal of Biotechnology, vol. 8, no. 17, pp. 4183-4188, 2009.

[17] L. Dargahi, K. Razavi-Azarkhiavi, M. Ramezani, M. R. Abaee, and J. Behravan, "Insecticidal activity of the essential oil of Thymus transcaspicus against Anopheles stephensi," Asian Pacific Journal of Tropical Biomedicine, vol. 4, pp. S589-S591, 2014.

[18] S. Küçükaydın, G. Tel-Çayan, M. E. Duru, M. Kesdek, and M. Öztürk, "Chemical composition and insecticidal activities of the essential oils and various extracts of two Thymus species: Thymus cariensis and Thymus cilicicus," Toxin Reviews, vol. 13, pp. 1-11, 2020.

[19] T. Ainane, F. Khammour, S. Charaf et al., "Chemical composition and anti-insecticidal activity of the essential oils of Thymus of Morocco: Thymus capitates, Thymus bleicherianus and Thymus satureioides," Organic \& Medicinal Chemistry International Journal, vol. 6, no. 3, Article ID 555687, 2018.

[20] F. Saidj, S.-A. Rezzoug, F. Bentahar, and C. Boutekedjiret, "Chemical composition and insecticidal properties ofThymus numidicus(poiret) essential oil from Algeria," Journal of Essential Oil Bearing Plants, vol. 11, no. 4, pp. 397-405, 2008.

[21] J. H. Park, Y. J. Jeon, C. H. Lee, N. Chung, and H. S. Lee, "Insecticidal toxicities of carvacrol and thymol derived from thymus vulgaris lin. against pochazia shantungensis Chou \&Lu., newly recorded pest," Scientific Reports, vol. 7, no. 1, pp. 40902-40907, 2017.

[22] J. Lazarević, S. Jevremović, I. Kostić et al., "Toxic, oviposition deterrent and oxidative stress effects of Thymus vulgaris essential oil against Acanthoscelides obtectus," Insects, vol. 11, no. 9, p. 563, 2020.

[23] P. M. Kumar, K. Murugan, P. Madhiyazhagan et al., "Biosynthesis, characterization, and acute toxicity of Berberis tinctoria-fabricated silver nanoparticles against the Asian tiger mosquito, Aedes albopictus, and the mosquito predators Toxorhynchites splendens and Mesocyclops thermocyclopoides," Parasitology Research, vol. 115, no. 2, pp. 751-759, 2016.

[24] D. Damtie, C. Braunberger, J. Conrad, Y. Mekonnen, and U. Beifuss, "Composition and hepatoprotective activity of essential oils from Ethiopian thyme species (Thymus serrulatus and Thymus schimperi)," Journal of Essential Oil Research, vol. 31, no. 2, pp. 120-128, 2019.

[25] WHO, "Deworming for health and development," in Report of the Third Global Meeting of the Partners for Parasite ControlWorld Health Organization, Geneva, Switzerland, 2005.

[26] R. Pavela, N. Vrchotová, and J. Tř́ska, "Mosquitocidal activities of thyme oils (Thymus vulgaris L.) against Culex quinquefasciatus (Diptera: Culicidae)," Parasitology Research, vol. 105, no. 5, pp. 1365-1370, 2009.

[27] M. G. Machani, E. Ochomo, D. Sang et al., "Influence of blood meal and age of mosquitoes on susceptibility to pyrethroids in Anopheles gambiae from Western Kenya," Malaria Journal, vol. 18, no. 1, p. 112, 2019.

[28] WHO, Guidelines for Testing Mosquito Adulticides for Indoor Residual Spraying and Treatment of Mosquito Nets, World Health Organization, Geneva, Switzerland, 2006.

[29] U. R. Bernier, D. L. Kline, K. H. Posey, M. M. Booth, R. A. Yost, and D. R. Barnard, "Synergistic attraction ofAedes aegypti(L.) to binary blends of L-lactic acid and acetone, dichloromethane, or dimethyl disulfide," Journal of Medical Entomology, vol. 40, no. 5, pp. 653-656, 2003.

[30] I. Amri, L. Hamrouni, M. Hanana, B. Jamoussi, and K. Lebdi, "Essential oils as biological alternatives to protect date palm (Phoenix dactylifera L.) against Ectomyelois ceratoniae Zeller (Lepidoptera: Pyralidae)," Chilean Journal of Agricultural Research, vol. 74, no. 3, pp. 273-279, 2014.

[31] M. R. Youssefi, M. A. Tabari, A. Esfandiari et al., "Efficacy of two monoterpenoids, carvacrol and thymol, and their combinations against eggs and larvae of the West Nile vector Culex pipiens," Molecules, vol. 24, no. 10, p. 1867, 2019.

[32] A. E. Livingston, "The comparative toxicity of thymol and carvacrol (isothymol)," Public Health Reports, vol. 43, pp. 1317-1331, 1921. 
[33] S. Andrade-Ochoa, D. Sánchez-Aldana, K. F. Chacón-Vargas et al., "Oviposition deterrent and larvicidal and pupaecidal activity of seven essential oils and their major components against Culex quinquefasciatus Say (Diptera: Culicidae): synergism-antagonism effects," Insects, vol. 9, no. 1, p. 25, 2018.

[34] V. Prasanth Reddy, K. Ravi Vital, P. Varsha, and S. Satyam, "Review on Thymus vulgaris traditional uses and pharmacological properties," Medicinal and Aromatic Plants Research Journals, vol. 3, no. 164, pp. 2167-0412, Article ID 1000164, 2014.

[35] R. Waliwitiya, P. Belton, R. A. Nicholson, and C. A. Lowenberger, "Effects of the essential oil constituent thymol and other neuroactive chemicals on flight motor activity and wing beat frequency in the blowflyPhaenicia sericata," Pest Management Science, vol. 66, no. 3, pp. 277-289, 2010.

[36] D. Wahyuni, "Larvicidal activity of essential oils of piper betle from the indonesian plants against Aedes aegypti L," 2012.

[37] A. Popoviæ, J. Šuæur, D. Orèiæ, and P. Štrbac, "Effects of essential oil formulations on the adult insect Tribolium castaneum (Herbst)(Col., Tenebrionidae)," Journal of central European agriculture, vol. 23, 2013. 